\title{
Leadership Applications for Sport and Recreation Service Leaders
}

\begin{abstract}
By Ioanna Maria Kantartzi $i^{*} \&$ George Karlis ${ }^{ \pm}$
Sport and recreation are closely linked service-oriented professions. Sport and recreation professionals and practitioners often share ideas and knowledge to increase understanding of leadership means and capacities to better serve. The purpose of this paper is to examine leadership while presenting applications for "good leadership" for the sport and recreation service industries. To fulfill this purpose, this paper introduces the notion of leadership and its styles. This paper concludes with five applications for "good leadership" for current and future sport and recreation leaders: (1) awareness of constant on-going change, (2) have a democratic approach, (3) effective communication skills, (4) maintain an open-door policy, and (5) enhance quality of life. Although this list of applications is not all-inclusive, it does depict critical attributes that sport and recreation service leaders should possess today and in the future.
\end{abstract}

Keywords: Leadership, sport, recreation, sport and recreation services

\section{Introduction}

During the $20^{\text {th }}$ century, research on leadership expanded at a rapid pace from multidisciplinary perspectives. Although much of the research conducted has come out of the field of business and administration, leadership has been researched in other fields of study such as politics, psychology, sociology, community development, sport, and recreation. Early $20^{\text {th }}$ century research on leadership looked at the relationship between leadership and personality (Van Seters and Field 1990). As Greenwood (1996) posits, the historical evolution of leadership was initially linked to an understanding of personality traits. Later, in the 1960s, research on leadership focused largely on understanding human relations and human interactions and the impact these had on work and motivation (Greenwood 1996).

Sport and recreation are two service-oriented professions that have a lot to contribute in the understanding of what leadership is and how it can be best practiced. In the early part of the $20^{\text {th }}$ century, sport and recreation continued to gain in importance, particularly with the expansion on urbanization and municipal recreation services (Karlis 2016). As cities grew, the need for recreation and other public services expanded. Thus, leaders came to the forefront to help guide, establish, and implement these services.

In the past 100 years, leadership has come a long way. Leadership helps us understand how important it is to lead, guide, and direct; it also helps us recognize the importance of planning, organizing, directing and implementing services.

${ }^{*}$ Phd Student, University of Ottawa, Canada.

${ }^{ \pm}$Professor, University of Ottawa, Canada. 
Existing research reveals, however, that there is not only one way to understand what leadership is, as it is a notion that has been defined in many different ways. Research in sport and recreation indicates that there are many different styles of leadership that can be implemented in sport and recreation services and settings (Karlis 2020).

The purpose of this paper is to, through a leadership review, examine leadership while also present applications for "good leadership" for the sport and recreation service industries. To fulfill this purpose, this paper introduces leadership and its styles, while concluding with five applications for "good leadership" for current and future sport and recreation leaders: (1) awareness of constant on-going change, (2) have a democratic approach, (3) effective communication skills, (4) maintain an open-door policy, and (5) enhance quality of life.

\section{Introducing Leadership}

Bolden et al. (2011), indicated that leadership is the combination of social influence, guidance, structural behaviours, activities, and relationships towards the achievement of shared aims. All these leadership characteristics shape a "property" of an effective systemic design in which leadership development includes commitments among the members of a community, as they are working together and are accountable to each other. This interconnection of community members indicates that social behaviour is an important development tool of "good leadership".

Leadership is a behavioural shaped notion. It is determined and largely shaped by norms and values of society, organizations, institutions, as well as the norms and values of people. Normative leadership for instance, refers to approaches of leadership that describe the most effective styles of leadership intervention. The normative leadership notion is applied to behavioural and situational leadership situations, but also to transformational, servant, and distributed organizations leadership styles (Bolden et al. 2011). The implementation of a normative leadership approach is largely shaped and determined by situation and culture.

Bolden et al. (2011) define leadership as a notion that consists of a number of essential characteristics. These include: (1) leadership as a factor contributing towards organizational performances, (2) leadership as a source of power on achieving goals (3) leadership as a set of competences which can be developed and assessed, (4) leadership as a strategic vision setting out the organization's future, (5) property and product of organizational culture, and, (6) leadership as a practice that is shaped by organizational context (Bolden et al. 2011). Thus, leadership is a tool for achieving collective groups' structure, organizing and reaching goals, and managing organizational performance.

A further conceptualization of leadership by Van Knippenberg and Hogg (2003) takes a more sociological approach. For Van Knippenberg and Hogg (2003) leadership refers to the patterns of social interactions between and amongst a group of people in organizations. Focus is given to the importance of the 
leadership process in directing people to increase productivity. As stated by Chemers (2003) the sociological approach of leadership focuses on the interrelationship and communication patterns used to achieve organizational and individual goals.

Pierce and Newstrom (2006) also define the concept of leadership and introduce different types of leadership styles. Leadership has a simple definition as it refers to the behaviour of individuals in which leaders provide guidance, and exert influence to their followers (Pierce and Newstrom 2006). Leadership is the relationship between the leader and a situation, that is, leadership and followers (Pierce and Newstrom 2006).

From the aforementioned conceptualizations of leadership it can be posited that one overarching perspective of leadership does not exist, as there are many ways of viewing the meaning of leadership. Perhaps a broader way of conceptualizing leadership is to identify its defining characteristics. Pierce and Newstrom (2006) do this while indicating that there are eleven approaches of leadership: (1) leadership as a focus of group processes, (2) leadership as personality and its effects, (3) leadership as an act or behaviour, (4) leadership as an instrument of goals, (5) leadership as an emerging effect of interaction, (6) leadership as a different role, (7) leadership as the initiation of structure, (8) leadership as the art of inducing compliance, (9) leadership as the exercise of influence, (10) leadership as a form of persuasion, and (11) leadership as a power relationship. The concept of leadership is thus complex and viewed according to many different perspectives (Bolden et al. 2011).

\section{Leadership Styles}

Many different leadership styles have been employed in sport and recreation organizations (Karlis 2020). For the purposes of this paper, eight popular leadership styles in sport and recreation services are presented. These include: (1) democratic, (2) autocratic, (3) laissez-faire, (4) strategic, (5) transformational, (6) transactional, (7) coach-style, and (8) bureaucratic (Becker 2020).

The democratic style is the most popular and common style of leadership employed (Becker 2020, Sharma and Singh 2013). This is largely attributed to the fact that leaders are supportive of listening to their teams' opinions, with decisions made in a democratic way. The democratic leadership style allows accessibility of employees and, in some cases, to service participants to voice opinions and get involved in decision-making. It is thus a favourable approach for organizational commitment and positive group dynamics.

On the contrary, in the autocratic leadership style, decisions and leadership actions come primarily and directly from leaders without consultation of subordinates. The autocratic leadership style is based on a hierarchy in which decisions come from above, and are made from executives or managers in leadership positions. Studies have shown that this style may have a negative impact on performance (Dolly and Nonvelum 2018). However, this style does have effective outcomes for larger sized organizations. 
The laissez-faire leadership style is the least intrusive form of leadership (Becker 2020). Laissez-faire is a French term that can be translated to "let them do" (Becker 2020). Often in the laissez-faire approach, members of an organization who do not have a leadership title will come forth and take the lead of certain initiatives. This style is known as absence of leadership, and may reduce the level of productivity (Tosunoglu and Ekmekci 2016).

The strategic style of leadership is one in which leaders not only accept burdens but also take measures to make sure that working conditions are appropriate for organizational members. According to Becker (2020) the strategic style of leadership may be applied in different situations, in different contexts, and needs to be treated carefully as its success depends on how many subordinates a leader can support at one time. According to Stumpf and Mullen (1991), the strategic leadership style stresses that the leader will be able to tap into concepts and skills, and process them in time to implement effective leadership.

The style that may be more effective than the others is the transformational leadership style. In the transformational leadership style, employees recognize individual tasks and weekly goals. However, the leader tries to get more out of their employees by expanding their capacity beyond their comfort zone. The leader challenges employees by giving them more and different goals and objectives, ultimately to make the organization more productive. The transformation leadership style can be an encouraging and a highly productive leadership approach, as it helps individuals to understand their limits and accomplish their goals (Becker 2020). The leader plays the role of the change agent while inspiring the subordinates to be more creative. Some of the main characteristics of this leadership style include influence, individualized consideration, intellectual stimulation and inspiration motivation (Ghasabeh 2017).

Leaders utilizing a transactional leadership style not only try to organize individuals, but also give them bonuses for achieving their goals. This bonus giving approach is employed by the transactional leadership style with a main goal to motivate individuals to better achieve personal and organizational goals as well as contribute to the development of the organization. Thus, this style provides a win-win scenario for both workers and the organization (Becker 2020). The transactional leadership style contributes to the satisfaction level of the subordinates and possibly to greater work performance efforts (Hussain et al. 2017).

The coach-style leadership style is an approach that has many similarities to sports coaching. In this style, leaders attempt to identify the strengths and limits of individuals while developing subordinates to achieve greater productivity in the organization. Coach-style leadership identifies means to make the organization work more cooperatively. Thus, the coach-style leadership approach emphasizes the importance of individual and team success (Becker 2020). Apart from its motivational character, in this style leaders hold responsibility and accountability in the leading process (Moen and Federici 2012).

Finally, the bureaucratic leadership style, according to Becker (2020), is infrequently effective, as all individuals have to work in accordance to stated guidelines. This means that every piece of the organizational puzzle needs to be 
connected and worked to the organizational goals and objectives. Thus, leaders lead to ensure working tasks abiding with organizational policies and practices.

A number of factors are important and relevant to consider when it comes to the success of a leadership style in sport and recreation organizations and services. Factors such as size, type of organizations (private, public, non-profit), goals to be achieved, resources at hand (human, material, and financial), etc., all play a key role in determining what leadership style is best employed. Each case specific situation needs to be careful considered in determining the leadership style that is best (Yukl 2004).

\section{Applications for "Good Leadership" for Current and Future Sport and Recreation Service Leaders}

Society and its people have come a long way in the last century, and so have the needs and expectations of sport and recreation services and their leaders. A lot is expected of a sport and recreation leader today. To fulfill these high expectations sport and recreation leaders may benefit by recognizing certain principles of "good leadership". Below, are some principles of "good leadership" that have been put together to guide current and future sport and recreation service leaders in delivering services.

\section{Awareness of Constant On-Going Change}

We are living in an ever-changing world. Technology and mass communication have a lot to do with the way we have changed, and the way that our sport and recreation needs, and expectations have changed as well. Sport and recreation leaders need to be cognizant at all times that we live in a generation of change. Sport and recreation needs constantly change. Clients of sport and recreation services have expectations to be served and have their sport and recreation needs served. As there is a plethora of sport and recreation needs in society as a whole, a "good leadership" principle that current and future sport and recreation leaders need to possess is an awareness of constant on-going change.

\section{Have a Democratic Approach}

As sport and recreation is a people service industry, the best leaders are the ones who listen to the people being served and the people affected by the sport and recreation services offered. Listening however is not enough. Sport and recreation leaders need to get those served involved in decision-making. Having a democratic approach means welcoming participatory input and allowing opportunity for sport and recreation participants to engage in decisions that have to do with the provision of sport and recreation services. Affording participants of sport and recreation services the opportunity to get involved goes a long way in enhancing the quality and satisfaction level of the sport and recreation service and experience. 
Thus, a very important principle of "good leadership" for current and future sport and recreation leaders is to have a democratic approach to leadership.

\section{Effective Communication Skills}

As the world changes, so does our means of communicating. We now have social media, emails, text messages, etc., which means that we can communicate with a mass group of people faster than ever before. Effective written communication skills are thus more important than ever. Being able to orally communicate in the official language(s) of your host nation is just as important. Despite the means used to communicate, sport and recreation leaders must have the ability to recognize and overcome any expressive and receptive blocks of communication. Sport and recreation leaders need to recognize that effective communication skills take effort and that time needs to be devoted to ensuring that messages are relayed and received as intended. The "good leadership" principle of effective communication skills is one that current and future sport and recreation service leaders need to constantly work on developing and perfecting.

\section{Maintain an Open-Door Policy}

The best sport and recreation service leaders are the ones that are accessible. Sport and recreation services leaders who are accessible are the ones available to answer questions, solve problems, and guide and direct. Thus, a sense of responsibility comes with being the leader. Sport and recreation service leaders need to be equipped with answers to questions, meaning that these leaders need to be well prepared and well informed on organizational details, resources, and services offered. Yet, this open-door policy goes beyond answering questions, it extends to making clients of services and co-workers feel important, that is, to recognizing that the sport and recreation leader is there for them.

\section{Enhance Quality of Life}

Sport and recreation leaders need to ensure that the environment for sport and recreation and the services of sport and recreation are positive. The success of the sport and recreation organizations depends on sound leadership, as this comes with continuous service and facility evaluation. Sport and recreation service leaders need to conduct regular formal and informal evaluations to ensure that the sport and recreation organization and its services are operating in a positive fashion and enhancing quality of life of all involved, including the participant.

\section{Conclusion}

Today, everything is important in sport and recreational services; from the way that services serve the public to the way that people in leadership positions support individuals in achieving their personal goals. Sport and recreation services 
are people-oriented services. Focus is on individuals or groups of people, who wish to achieve their personal goals and further develop their lifestyle. Successful sport and recreation services are those that are well managed with "good leadership". "Good leadership" is the tool that helps both the sport and recreation services and individuals, to achieve individual, collective, and organizational goals.

Leadership has a great impact on all. Change is inevitable, and leaders are thus called to take on greater challenges than ever. Being a good, efficient, and effective leader is no easy task. It is a skill and talent that cannot be learned only in the classroom, but it rather takes time, knowledge, and experience to develop.

This paper, while focusing on the sport and recreation service industries provided a general overview of the concept of leadership and leadership styles. It concluded with suggestions for "good leadership" for current and future sport and recreation service leaders. Although by no means is the list of five applications all inclusive; this list does depict critical attributes that sport and recreation service leaders must possess today and, in the future, to govern services towards enhancing the quality of life of society.

More research is needed to help understand current trends and directions of the sport and recreation service leadership, as little research has been conducted in the field. Future research should expand on examining case studies of leadership experiences in sport and recreation service organizations to recognize what is happening and what needs to be changed. Future research should focus on the differences in sport and recreation leadership styles in the three sectors -public, private, and non-profit- as it would also make an important contribution to research on leadership and the recreation service industry as well.

\section{References}

Becker B (2020) The 8 most common leadership styles \& how to find your own. HubSpot Blog. Retrieved from: https://blog.hubspot.com/marketi ng/leadership-styles.

Bolden R, Hawkins B, Gosling J, Taylor S (2011) Exploring leadership: individual, organizational \& societal perspective. Oxford: Oxford University Press.

Chemers MM (2003) Leadership effectiveness: functional, constructivist and empirical perspectives. In D Van Knippenberg, MA Hogg (eds), Leadership and Power, Identity Processes in Groups and Organizations. Sage Publications.

Dolly KC, Nonyelum OP (2018) Impact of autocratic leadership style on job performance of subordinates in academic libraries in Port HarCourt, Rivers State, Nigeria. International Journal of Research - GRANTHAALAYAH 6(10): 212-220.

Ghasabeh MS (2017) Transformational leadership: building an effective culture to manage organizational knowledge. Journal of Values Based Leadership 10(2): Article 7.

Greenwood RR (1996) Leadership theory: a historical look at its evolution. The Journal of leadership Studies 3(1): 3-16.

Hussain ST, Abbas J, Lei S, Haider MJ, Akram T (2017) Transactional leadership and organizational creativity: examining the mediating role of knowledge sharing behaviour. Cogent Business \& Management 4(1): 1361663.

Karlis G (2016) Leisure and recreation in Canadian society. $3^{\text {rd }}$ Edition. Toronto: Thompson Educational Publishing. 
Karlis G (2020) Sport, recreation and community development. Champaign, IL: SagamoreVenture.

Moen F, Federici RA (2012) The effect from coaching based leadership. Journal of Education and Learning 1(2): 1-14.

Pierce JL, Newstrom JW (2006) Leaders and the leadership process. readings, selfassessments $\&$ applications. $4^{\text {th }}$ Edition. Boston, MA: Mc Grawn-Hill Irwin.

Sharma LJK, Singh SK (2013) A study on the democratic style of leadership. International Journal of Management \& Information Technology 3(2): 54-57.

Stumpf SA, Mullen TP (1991) Strategic leadership: concepts, skills, style and process. Journal of Management Development 10(1): 42-53.

Tosunoglu H, Ekmekci OT (2016) Laissez-Faire leaders and organizations: how does Laissez-Faire leader erode the trust in organization. Journal of Economics, Finance and Accounting 3(1): 89-99.

Van Knippenberg D, Hogg MA (2003) Leadership and power, identity processes in groups and organizations. London: Sage Publications.

Van Seters DA, Field RHG (1990) The evolution of leadership theory. Journal of Organizational Change Management 3(3): 29-45.

Yukl G (2004) The future of leadership research: challenges and opportunities. German Journal of Human Resource Research 18(3): 359-365. 